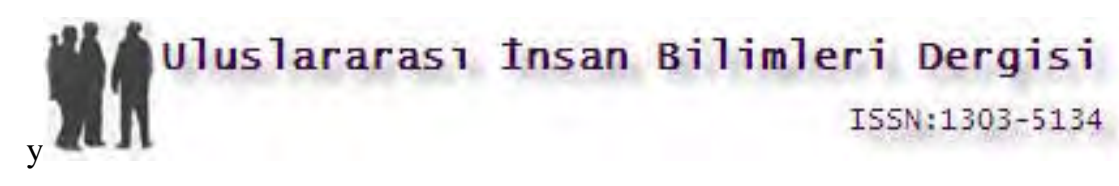

Cilt:5 Sayı:2 Yll:2008

doi: $10.14687 /$ ijhs.v5i2.574

\title{
Bir toplumsallaştırma aracı olarak eğitimde alternatif medya kullanımı: Sinema filmleri
}

\author{
Mehmet Cüneyt Birkök ${ }^{1}$
}

\begin{abstract}
Özet
Çalışma konusu bir toplumsallaştırma aracı olarak sinema filmlerinin eğitimdeki işlevlerini değerlendirmektir. Daha yararlı kullanılabilmesi için sistematik düzenlemeler yapılmasına dikkat çekmek amaçlanmaktadır. İçerik analizi ve gözlem tekniklerinin birlikte kullanıldığı bir yöntem izlenmiştir. Elde edilen bilgiler 1şığında iki önemli unsura dikkat çekmek gerekmektedir. Bunlardan ilki, sinema filmlerinin karmaşık bilimsel konulardan davranış biçimlerine kadar her tür ve nitelikte bilgiyi en etkin biçimde aktarabilecek bir araç olduğudur. İkincisi ise, okuduğunu anlama becerisinin giderek azalmasıdır. $\mathrm{Bu}$ problemin nedeni olarak görsel iletişimin hakim olması tahmin edilmektedir. Çalışmada sinema filmlerinin eğitim aracı olarak kullanılmasının çeşitli örnekleri incelenmekte toplumsallaşma açısından değerlendirilmektedir.
\end{abstract}

Anahtar Sözcükler: film, toplumsallaşma, eğitim

\section{Alternate media usage in education as a socialization tool: Movies}

\begin{abstract}
The subject of the article is to evaluate some of the important functions of cinema movies as a socialization tool. The article is aimed to show that some regulations must be accomplished in order to utilize movies in education more efficiently. Content analysis and observations are two methodological techniques that used preparing in this work. Two important issues are remarked. First, movies are most effective tools that are able to transfer any kind of knowledge from complex scientific subjects to social attitudes and behaviors. Second, the reading comprehensiveness of the students decreases gradually. The reason is that the dominance of the visual media is estimated. In this study, some representable examples of movies as educational tool are examined and commented from the point of socialization.
\end{abstract}

Key Words: movie, socialization, education

\footnotetext{
${ }^{1}$ Sakarya Üniversitesi, Eğitim Fakültesi, Eğitim Bilimleri Bölümü, Hendek-Sakarya, birkok@,sakarya.edu.tr
} 


\section{GíRiș}

$\mathrm{Bu}$ bildirinin konusu, benzersiz bir toplumsallaştırma aracı olarak sinema filmlerinin eğitimdeki işlevlerini değerlendirmektir. Sinema filmlerinin toplumsallaştırma ve eğitimdeki gücü, başlıca iki ana nedene dayanmaktadır. İlk neden, bizzat sinema sanatının nitelikleri ile ilgilidir. İkinci neden ise bilgi teknolojileri ve eğitim stratejilerindeki gelişmelerdir. $\mathrm{Bu}$ çalışmada, toplumsallaşmada bilgi aktarım araçları olarak sinema filmlerinin söz konusu nedenlere bağlı değerlendirilmesi yapılarak, eğitim stratejileri açısından nasıl kullanıldığı ve gelecekte ağırlıklı olarak hangi nedenlerle ön plana geçebileceği tartışılacaktır.

Çalışmada güdülen amaç, sinema filmlerinin eğitimde kullanım zorunluluğuna dikkat çekerek eğitim çevreleri tarafından gereken sistematik düzenlemelerin yapılmasını sağlamaktır. Sinemanın onca özgün yararı, eğitimcilerin kişisel becerilerine yüklenmeyerek, kurumsal düzenlemelerle sistematik olarak sağlanmalıdır.

Bu çalışmada içerik analizi ve gözlem tekniklerinin birlikte kullanıldığı bir yöntem izlenmiştir. Konu ile ilgili olarak daha önce yapılmış olan çeşitli saha araştırmaları bulguları, çıkarsamalar, değerlendirmeler ve yorumlar incelenerek genel saptamalar elde edilmiştir. Araştırmanın yol gösterici varsayımı doğrultusunda bu bilgiler çözümlenerek yorumlanmıştır.

Elde edilen bilgiler genel olarak değerlendirildiğinde, ters yönde iki ana olgunun ortaya çıktığı görülmektedir. Bunlardan ilki sinema sanatının kendine has özellikleri nedeniyle toplumsallaşmada/eğitimde en etkin bir araç olarak kullanılabilirliğidir. Diğeri de, görsel araçların yoğun kullanımının, aynı zamanda, insan zihninin büyük ölçüde okuduğunu anlaması becerisini azaltmasıdır. Bu ikinci olgu, çalışmanın konusu değildir ve bu nedenle ayrıntılı olarak ele alınmayacaktır. Ancak mutlaka işaret edilmesi ve derhal etkin tedbirlerin alınması gereken çok ciddi ve tehlikeli bir problemdir.

$\mathrm{Bu}$ çalışmanın esas konusu olan sinema filmlerin toplumsallaştırma açısından nitelik itibariyle iki önemli özelliği bulunmaktadır. Bunlardan birincisi teknik olarak bir filmin görüntü, hareket ve ses unsurlarının bir arada kullanılabilmesiyle çok büyük miktarlarda bilginin aktarılabilmesine olanak vermesidir. Kıyaslayarak ifade etmek gerekirse, birkaç saatlik bir filmde bulunan görsel ve işitsel tüm unsurların tümünün yazılı bir metin olarak kaydedilebilmesi, hele izleyiciye aktarılabilmesi, neredeyse imkansızdır. Ses veya duygu gibi soyut manaların aynı şekilde yazılı olarak algılanabilmesi ise tamamen imkansızdır. Bu gibi 
olguların nakli için sinema filmleri zaten en yaygın ve etkin bir araçtır. Filmlerin toplumsallaştırma bakımından ikinci önemli özelliği ise, sinemanın kendisinin bir sanat olması, başka bir deyişle, sosyal olguların ve düşüncelerin gerçek manaları ile duyguları aktarabilecek bir nitelikte olmasıdır. Bu özellik, elbette sinemanın diğer her tür işlevinden daha önemlidir. Bir ders kitabındaki herhangi bir metinde anlatılan bir sosyal normu, bir film sahnesinde olabileceği kadar öğrenciye anlatılabilmesi, ve bundan çok daha önemlisi, hissettirebilmesi ve öğretebilmesi mümkün değildir. Kısaca filmler, soyut bilgileri ilgili tüm unsurlarıyla bir bütünlük içinde eksiksiz olarak canlandırabilmekte veya gerçek bir hayata dönüştürebilmektedir.

Öte yandan teknolojik gelişmeler klasik eğitim araçlarının önemini artırmış, onlara yeni işlevler yüklemiş ve yepyeni eğitim araçları ortaya çıkarmıştır. Tanınmış bilim adamlarının ürettikleri bilgiler, örneğin video konferansları, internet aracılığıyla istenildiği zaman elde edilebilmekte, yada bir ülkenin tüm tarihiyle ilgili önemli kültürel, hukuki veya siyasi belgeler, resimler, haritalar, ses kayıtları, film kayıtları gibi her tür bilgi unsuru bir eğitim malzemesi olarak kullanılabilmektedir. $\mathrm{Bu}$ arada film aracı ve işlevi de giderek gelişmekte ve yaygınlaşmaktadır. Sinema filmleri fen ve sosyal bilimlerdeki hemen tüm branşlardaki herhangi bir olgunun öğretilmesi için kullanılabilmektedir.

\section{DEĞERLENDİRME}

\section{Sinemanın eğitimdeki toplumsal işlevleri}

\section{Toplumsallaştırma aracı olarak sinema}

Günümüzde sinema sektörü giderek büyümektedir. Bu büyüme ile birlikte sinemanın toplumsal işlevleri de giderek artmaktadır. Bunlardan en önemli ve öncelikli olanı, sinema aracılığıyla bilgi aktarma, başka bir deyişle sinemanın eğitimde kullanılmasıdır. Eğitilenlere, günlük hayatlarında karşılaşacakları olaylara yaratıcı bir tarzda cevap vermeyi öğretebilmektedir. Kitap veya oyunun katkısından çok daha fazlasını, insan hayatındaki ümidin, cesaretin, sevginin, sadakatin, kaybetmenin, korkunun, kısaca tüm ilişkilerin anlamını çok geniş bir ilişkiler ve manalar ağı içinde verebilmektedir (Paquette, 2003). Filmlerde ortaya konulan problemler bir bakış açısı oluşturabilmektedir. Hikayeler, destanlar ve mitoslar gibi eski eserlerin işlevlerinden çok daha önemlisini çok daha etkili bir şekilde, günümüzde yaşadığımız karmaşık hayatı incelemeyi, anlamlandırmayı ve neticede hem bireysel hem de 
Birkok, M., C. (2008). Bir toplumsallaştırma aracı olarak eğitimde alternatif medya kullanımı: Sinema filmleri. Uluslararası Insan Bilimleri Dergisi [Bağlantıda]. 5:2. Erişim: http://www.insanbilimleri.com

toplumsal bir bakış açısı oluşturmayı sağlamaktadır. Kişisel olarak olgular karşısında nasıl davranılması gerektiğini, somut tutum ve davranış örnekleriyle açıklamaktadırlar. İnsanlar arasındaki önyargıları kırabilmekte, kesimlerin veya nesillerin birbirini anlamasını sağlayabilmektedir (Wilson, 2002). Tüm bir toplumu ilgilendiren konularda davranış örnekleriyle beraber temel noktalar, açık ve anlaşılır biçimde ifade edilebilmektedir. Geniş kitlelere ulaşmak açısından televizyon dizileri son derece etkin olmaktadır. Türkiye'de yapılan bazı televizyon dizilerinin Orta ve Uzak Doğuda, Avrupa ve Güney Amerika’daki halklar tarafından ilgiyle izlendiği bilinmektedir. Böylece bir konunun uluslaraarası boyutuna müdahale etmek imkanı da doğmaktadır. Bu duruma bir örnek olarak, Türkiye’nin Ermeni meselesi ile ilgili olarak ortaya koyduğu bilgiler, bir TV dizisinde şöyle dile getirilmektedir: http://blip.tv/file/1495594 (Pana Film, 2006).

Öğrencilere özellikle uyuşturucu kullanımı ve diğer sosyal problemler (Wilson, 2003) gibi kavranması zor olan davranışlarla ilgili bilgileri aktarmak için kullanılabilmektedir. Basit bir bilgi sunumu işlevinin ötesinde, sosyal yapı için çok önemli bir olgu olan kültürleştirmede de filmler etkin bir araç olarak kullanılabilir (Kramer, 2004). İzleyiciler filmlerdeki pedagojik klipleri kolaylıkla kabul etmektedirler (Osborne, 2002). Tüm bu işlevler sinema filmlerinin son derece etkin bir eğitim ve dolayısıyla toplumsallaştırma aracı olduğunu ortaya koymaktadır.

Sinema filmleri, hem görsel hem de işitsel olarak yoğun bilgi içermek ve aktarmak olanağının yanı sıra, bu bilgilerin derin manalarını da sinema sanatı sayesinde izleyiciye iletebilmektedir. Sinema sanatının kullanılması, eğitim olgusu bakımından çok önemli ve etkin bir unsurdur; "görmek inanmaktır" özdeyişi bu güçlü etkiyi ifade etmektedir. Filmler karmaşık bilgileri imaj yardımıyla metinlere göre daha kolay anlaşılmasını sağlamaktadır. Ayrıca bilgi aktarımının, yani öğretimin yanı sıra, davranış modelleri de öğrenciye aktarılarak eğitim de sağlanabilmektedir. $\mathrm{Bu}$ nedenlerle sinema filmleri, sadece öğretim araçlarının zenginleştirilmesi olarak düşünülmemelidir. Kendi başına bir öğretim ve eğitim unsuru olarak görülmelidir.

Geleneksel olarak sınıfta ders anlatmak şeklinde yapılan eğitimi tamamlamak, sosyal gelişmeyi sağlamak ve toplumsal ahlakı öğretmek için gelişen teknoloji sayesinde kolaylıkla sağlanabilen sinema filmleri, uzun süreden beri eğitim ve öğretimde kullanılmaktadır. Müfredat malzemesi olarak kullanılabilecek mevcut filmler esasen çok geniş bir konu alanını kapsamaktadır; bilim, görsel sanatlar veya tarih gibi en genel konulardan, kriz ortamlarında aile, sosyal dayanışma, uyuşturucu kullanımı veya insan hakları gibi en özgün konulara kadar 
toplumda gözlemlenebilen her tür sosyal olguyu içerebilmektedir (Frieden \& Elliott, 2007). $\mathrm{Bu}$ nedenle hem esas hem de yardımcı kaynak olarak çok geniş bir konu alanında kullanılabilmektedir.

\section{Ders malzemesi olarak filmin eğitimde kullanılması}

Eğitimde sinema filmleri, genel olarak teknolojik gelişmeler çerçevesinde ele alınmaktadır. Yeni teknolojilerin öğretime ve eğitime radikal katkılar sağladığı ortadadır. Tanınmış bilim adamlarının ürettikleri bilgiler, örneğin video konferansları, internet aracılığıyla istenildiği zaman elde edilebilmekte, yada bir ülkenin tüm tarihiyle ilgili önemli kültürel, hukuki veya siyasi belgeler, resimler, haritalar, ses kayıtları, film kayıtları gibi her tür bilgi unsuru, bir eğitim malzemesi olarak kullanılabilmektedir (Appleford \& Burton, 2008). Teknolojik gelişmeler klasik eğitim araçlarının önemini artırmış, onlara yeni işlevler yüklemiş ve böylece yepyeni eğitim araçları ortaya çıkarmıştır.

Öte yandan, işlenen konu itibariyle de sinema ve edebiyatın eğitimde kullanılmasının tamamen orijinal örnekleri de bulunmaktadır. Geçmiş dönemlerdeki çeşitli önemli olayları anlatan sinema filmleri, belgeseller ve dizi filmler bunlardan bazılarıdır. Bu olaylar, roman türü edebi eserlerle de ele alınmaktadır. Ancak henüz salt eğitim amaçlı belli bir bilimsel konuyu ele alan sinema filmleri yaygın olarak çekilmemektedir. Önümüzdeki dönemlerde eğitim modelleri ve stratejileri için filmler, vazgeçilmez bir eğitim aracı olma yolunda ilerlemektedir. Günümüzdeki bilgi aktarım stratejilerinde, giderek bilginin canlı bir süreç içinde oluşturulması ve bireyin de bu süreçte aktif olarak yer alması sağlanmaya çalışılmaktadır. Buluş yoluyla öğretim veya proje tabanlı eğitim, bu stratejilerin kullandığımız yaklaşım açısından çeşitli örnekleridir.

Çeşitli sinema filmleri önceden belirlenmiş pek çok özgün amaç için hazırlanmakta ve kullanılmaktadır. Ancak ne yazık ki sinema literatürü incelemelerinde bu amaçların, filmlerin içerdiği konulara göre henüz verimli ve net bir tasnifinin yapılmadığı görülmektedir. Genellikle yüzeysel bir değerlendirme ile filmin içeriği ve kullanılabileceği konular işaret edilmektedir. Edebiyat, tarih, sanat tarihi, sosyoloji, psikiyatri gibi doğrudan kullanılabilecek alanlarda bile, derinliğine yapılmış film incelemeleri, değerlendirmeleri ve tasnifleri bulunmamaktadır (Lewis, 2003). Bu nedenle film incelemeleri çok önem verilen ve yaygın bir bilimsel çalışma branşı olmalıdır. 
Birkok, M., C. (2008). Bir toplumsallaştırma aracı olarak eğitimde alternatif medya kullanımı: Sinema filmleri.

Uluslararası İnsan Bilimleri Dergisi [Bağlantıda]. 5:2. Erişim: http://www.insanbilimleri.com

Bununla birlikte, bir filmin klasik kitaplara üstünlüğü tartılamaz boyutlardadır. Matbu kitaplarda ders konusu ile ilgili olarak sadece yazılı bilgi ve resim aktarılabilmektedir. Kitaptaki yazılı bilgi esasen durağandır ve etkinliği okuyucunun bilgiyi işleme eylemlerine bağlıdır. Öğrenci, okuma işlemini devam ettirmediği taktirde bilgi akışı kesilmektedir. Oysa film aracında, izleyicinin gayretine bağlı olmaksızın, kurgulanmış olan bilginin tümü dinamik bir şekilde hem görsel hem de işitsel olarak aktarılabilmektedir. Eğitilen kişilerin, eğitim işleminin gerektirdiği ölçüde disipline olup, bilginin aktarım sürecinin sonuçlanmasını bekleyerek, bilginin bir bütünsellik içinde kazanılmasını sağlamaktadır. Öte yandan yine bilgi aktarmada kullanılan bilgisayar programlarında ise, böyle bir avantaj bulunmamaktadır. Kullanıcı, dilediği zaman bilgi aktarımı işlemini kesebileceği için, o ana kadar edinmiş olduğu birikimleri kaybetme riskiyle karşı karşıyadır.

Derslerde filmlerin etkili olmasının en önemli sebeplerinden birisi, yeni nesillerin görsel medyaya çok aşina olmalarıdır (Luis Alvarez ve diğ., 2004). İzleyiciler sürekli olarak televizyon, video, film gibi her tür görsel medya etkisine maruz kalmaktadırlar. Filmlerde görselliğin yanı sıra, son derece etkin olan ikinci bir bilgi aktarma yolu olan işitsellik de kullanılmaktadır. Ses ile bilgi aktarımı ve eğitim, konuşma, müzik ve bir takım ses efektleri şeklinde olmaktadır. Sinema filmleri aracılığıyla müziğin de eğitimde kullanılması, hayat boyu kullanılacak olan eleştirel düşünme, problem çözme gibi temel kazanımları sağlayacaktır (White \& McCormack). Çoğu kez bu türlerin hepsi birlikte kullanılarak beklenen etki en yüksek seviyeye ulaştırılmaktadır. Öte yandan, müziğin eğitimde özgün bir önemi de vardır. Sözel değil, ama sanat diliyle bir müzik parçası öğrenciye belli bir duyguyu aktarabilme veya en azından onun duygusal yapısını, öğretilmek istenen bilgiye elverişli bir şekle dönüştürebilmektedir. Özellikle gençlik kültüründe müzik, çok temel, etkin ve yaygın bir unsurdur.

\section{Bazı uygulama örnekleri}

Sinema filmleri, olaylardaki insan boyutunu açıklamakta kullanılabilecek en mükemmel araçlardır. Bu olağanüstü değerlerine ve işlevlerine rağmen, maalesef, mütevazı ve sınırlı bir şekilde bir bilim dalının giriş mahiyetindeki genel özelliklerini anlatmakta, yada tarihe mal olmuş büyük bilim adamlarının hayatlarının bir tür kronolojik anlatımında kullanılmaktadır. Örneğin "Kimyaya Giriş” dersi için kaynak malzeme olarak kullanılan iki sinema filminde, bu dalda kullanılan yöntemler anlatılmaktadır (Griep \& Mikasen, 2005). Bilgi işlem teknolojisiyle üretilmiş diğer araçlar da son derece etkin olarak eğitimde 
Birkok, M., C. (2008). Bir toplumsallaştırma aracı olarak eğitimde alternatif medya kullanımı: Sinema filmleri.

Uluslararası İnsan Bilimleri Dergisi [Bağlantıda]. 5:2. Erişim: http://www.insanbilimleri.com

kullanılmaktadır. Örneğin hemen her konudaki enteraktif oyunlar, yap-boz oyunları, filmler, okuma metinleri, ders planları, dijital laboratuarlar, simülasyonlar gibi bilgi işlem araçlarıyla üretilmiş malzemeler bilgi ağı aracılığıyla hedef kitleye yaygınlaştırılmaktadır (Luch, 2007). Eğitim araçlarındaki uygulama örnekleri gelişen teknolojiye paralel olarak nitelik ve kullanım alanı itibariyle adeta sınırsız bir derinliğe ilerlemektedir.

Somut uygulama olarak ele alabileceğimiz örneklerden biri, psikoloji alanında, belirli bir akıl hastalığının hemen tüm yönleriyle net bir şekilde tanıtılması, önemli unsurlarının vurgulanması, örnek olayların örnek vakıalar aracıllğıyla incelenerek öğretilmesinin sağlanabilmesidir. Bu amaç doğrultusunda hazırlanmış olan yapıtlarda, öğrenciler filmlerde sergilenen karakterleri analiz edebilmekte ve ilgili olaylara ve açıklamalara bağlayabilmektedirler. Öğrenciler için aynı zamanda çok cazip ve eğlendirici bir eğitim tarzı içinde hem bilginin uygulanması gösterilmekte, hem de zihinlere anlamlı ve kalıcı olarak yerleştirilmesi sağlanmaktadır. Bu konu ile ilgili olarak uygulanan bir projede öğrencilerden elde edilen sonuçlar, öğrencinin filmi izledikten sonra teorik içeriği çok daha iyi anladıklarını ve öğrenme işleminin çok verimli, zevkli ve anlamlı olduğunu ortaya koymuştur (Sullivan Kerber, Clemens, \& Medina, 2004). Ayrıca öğrencilerin kişisel seviyede kendilerini anlamalarını, çevrelerinde ise bu olayların nasıl vuku bulabileceğini sosyal seviyede kavramalarını sağlamıştır. Bu projede, önce ders kitabındaki ilgili teorik bilgi konularında öğretim üyesi tarafından listeler hazırlanmış ve öğrencinin bir adet film seçmesi istenmiştir. Ayrıca yine öğretim üyesi tarafindan onaylanan ikinci bir film daha seçmesi sağlanmıştır. Öğrenciden bu iki filmi izleyerek eleştirel düşünmeyi sağlayan beş adet sorunun cevaplarını oluşturacak bir sunum hazırlanması istenmiştir. $\mathrm{Bu}$ sorular filmlerden beklenen yararları göstermesi bakımından önemlidir. Öğrencilerden hazırlanması istenen cevaplar şunlardır:

1. "İzlediğiniz filmlerdeki karakterlerde canlandırılan psikolojik bozuklukların belirgin özellikleri nelerdir?

2. Canlandırılan zihinsel hastalıkta, tedavide ve sağlık personelinin rolünde nasıl bir toplumsal veya kültürel tavır yansıtılmaktadır?

3. Filmdeki karakterlere olan tepkinizi betimleyiniz.

4. Psikiyatrik tedavi bilginiz filme veya filmdeki karakterlere olan tepkinizi değiştirmekte midir?

5. Bir akıl hastalığının veya tedavisinin, hastalar, aileler, nüfus veya sağlık personelince, daha iyi anlaşılmasını sağlamak için bu filmi nasıl kullanırdınız?” (Sullivan Kerber ve diğ., 2004, s. 479). 
Birkok, M., C. (2008). Bir toplumsallaştırma aracı olarak eğitimde alternatif medya kullanımı: Sinema filmleri.

Uluslararası Insan Bilimleri Dergisi [Bağlantıda]. 5:2. Erişim: http://www.insanbilimleri.com

Bu sorular aynı zamanda bir konunun sinema filmi aracılığıyla ne kadar geniş ve derin boyutlarda kolaylıkla ele alınabileceğini, işlenebileceğini ve kavranabileceğini göstermektedir.

Öte yandan tamamen ayrı bir tarz ve konu olarak çizgi filmlerin ilk eğitimde kullanılmasının bir örneği, ABD Ulusal Bilim Vakfı (National Science Foundation) tarafından okul öncesi kız öğrencilerin problem çözme becerilerini geliştirmeyi amaçlayan mühendislik dalında hazırlanmış çizgi filmler dizisidir. Bu dizide insan biçimindeki (anthropomorphic) makine parçaları ve mühendislik formülleri birbirleriyle etkileşime girerek mühendislik ekonomisi, termodinamik, akışkanlar mekaniği, katı cisim mekaniği, malzeme mekaniği, elektrik devreleri ile bilim ve mühendislik tarihindeki temel problemleri ve çözümlerini anlatmaktadırlar (Xueshu Song, 2003). Tüm çizgi filmlerde, doğa kanunları ile bunların keşfedilmesi, yayılması ve uygulanması bir bütünlük içinde gösterilmekte ve ortak özellikleri ön plana çıkarılarak vurgulanmaktadır. Böylece okul öncesi seviyesinde, ancak en temel konularda bir bilgi aktarımının yanı sıra, problem çözme ve yaratıcılık becerileri de geliştirilebilmektedir. Bu çizgi film dizisinden elde edilen çok önemli bir diğer yarar da realizmin romantizmle, sanatın bilimle, özelin genelle, ve popüler kültürün ise okul öncesi mühendislik eğitimiyle birleştirilmesidir (Xueshu Song, 2003). Bu filmlerin katkısı ile ilgili olarak yapılan bir araştırmada, okul öncesi kız öğrencilerin temel mühendislik problemlerinin çözümünde, büyük ölçüde tutumlarının geliştiği ve beceri kazandıkları ortaya çıkarılmıştır (Xueshu Song, 2003). Görünen odur ki, çok karmaşı bilimsel konular, ilk eğitim seviyelerindeki genç zihinlere bile rahatlıkla aktarılabilmektedirler.

Filmlerin dil öğreniminde kullanılması ise bir başka çarpıcı örnektir. Bu uygulamada özel olarak dil eğitimi amaçlayan filmler çevirmek yerine, mevcut bir film 20 dakikalık parçalara ayrılmakta ve içeriğiyle ilgili olarak yazımların, egzersizlerin, dilbilgisi ve kelime bilgilerinin bulunduğu bir kitapçık öğrenciye verilmektedir (Anonymous, 2007). Bu yöntem, eğitime uygun tüm yaş grupları için, genel olarak dil öğrenmeden belirli bir sınava hazırlanmaya kadar çok geniş bir amaç yelpazesinde etkili bir şekilde kullanılabilmektedir. Dil öğretmenleri için materyal geliştirmede kullanılan (Kramer, 2004) pek çok başka örnek bulunmaktadır.

Sinema filmleri karmaşı bilimsel, sosyal veya edebiyat teorilerini anlamak ve öğretmekte kullanılan çok etkin bir unsurdur. Dekonstrüksiyon gibi yeni yöntemlerle filmler incelenerek yeni edebiyat akımları veya karmaşık bir edebiyat teorisi çözümlenebilmektedir (Muller, 2006). Sinema filmleri ve daha geniş bir kapsamla dizi filmler veya televizyon 
Birkok, M., C. (2008). Bir toplumsallaştırma aracı olarak eğitimde alternatif medya kullanımı: Sinema filmleri. Uluslararası İnsan Bilimleri Dergisi [Bağlantıda]. 5:2. Erişim: http://www.insanbilimleri.com

gösterileri sadece bir bilgi aktarmakla kalmamakta, çeşitli sosyal mesajlar da vermektedir (Bumpus, 2005). Filmlerdeki diyaloglar ve bilgiler insan hafizasında diğer yollardan edinilmiş bilgilere göre daha kalıcı olmaktadır. Özellikle bu araçların yoğun olarak kullanıldığı ve kültürel olarak yapılandığı gelişmiş ülkelerde, muhtemelen eğitim ve kültürel seviyelerin yüksekliği nedeniyle, öğrenme ve hatırlama etkisinin arttığı düşünülmektedir. Ayrıca bu tür ortamlarda bir kültür kaynağı olarak da işlev görmektedir. Sözgelimi filmlerdeki olaylar veya replikler kültürel örnekler olarak uzun zaman hatırlanmakta ve kullanılmaktadır (NortonMeier, 2005). Böylece sinema filmlerinin işlevi, sadece bir aktarım aracı olmaktan çıkıp, kendi başına bir anlamı olan kapsamlı bir kültür unsuruna dönüşmektedir.

Öte yandan, sinema filmlerinin, çeşitli konuların ve kavramların yansıtılmasında, teori uygulamalarının gösterilmesinde, geleneksel yöntemlerden çok daha fazla güdüleyici ve canlandırıcı bir pedagojik malzeme kaynağı sağladığı da gözlemlenmektedir. Özellikle 1970'lerden sonra video, DVD ve internetteki gelişmelerle bu tür kavramsal filmlerin eğitimde kullanılması çok büyük ölçülerde artmıştır. Bu yaygınlığın nedeni filmin açıklayıcı ve güdüleyici niteliğinde yatmaktadır (Huczynski \& Buchanan, 2004). İzleyici (öğrenci), bulunduğu ortamdan alınarak ekrandaki bambaşka bir dünyada ve olaylar içinde aşkın bir tecrübe yaşatılmaktadır. Filmler, diğer medya araçlarında bulunmayan iki önemli unsuru, eğlendirmeyi ve öğretmeyi birlikte sağlamaktadır.

Filmler vaka incelemesi, problem çözümlemesi, metaforların (mecaz) gösterilmesi, sembolik iletişim, soyut düşünceleri somutlaştırmada, çeşitli tecrübeler kazanmada, tarihsel olayları göstermede kullanılabilir (Huczynski \& Buchanan, 2004). Ders kitaplarından çok daha anlamlı, etkileyici ve dinamik etkiler sağlamaktadır. Gerçek hayattaki olayları oldukları gibi, en azından ders kitaplarındaki çok basitleştirilmiş modellerden daha gerçekçi bir şekilde sunmaktadırlar. Bu bağlamda öğrencilerin derslerinde bir proje oluşturarak bununla ilgili bir film çekmeleri de (Luis Alvarez, Miller, Levy, \& Svejenova, 2004), eğitim faaliyetinin öğrenciler açısından gerçekleştirilen çok önemli bir yönünü ortaya koymaktadır.

Bu konu çerçevesinde son bir nokta olarak gözlemlenen çok önemli bir problemi işaret etmek gerekmektedir. $\mathrm{Bu}$ problem, okuduğunu anlama becerisinin gerektiği kadar gelişmemesi ve hatta eğitimi baltalayacak kadar etkinliğinin azalmasıdır. Muhtemelen film gibi görsel ve işitsel araçların çok yoğun kullanımı ve diğer bilgi aktarma araçların etkisinin azalması, bazı durumlarda vazgeçilmez bir önemi olan okuyarak anlama becerisinin de azalmasında neden olmaktadır. Modern sosyal yaşamda televizyon, sinema, video, bilgisayar ve resimli metinler gibi görsel unsurlar tarafından kuşatılmış durumdayız. Bu yoğun görsellik 
bombardımanı, öğrencinin okuduğunu da aynı oranda anlamasını sağlamamaktadır. Yapılan bir araştırmada bildirildiğine göre, öğrenciler, okunan bir metindeki bilgilerin anlaşılması ve zihinde canlandırılmasında büyük güçlükler çekmişlerdir. Bu öğrencilerin durumu "bir resim bin sözcükten daha anlamlıdır” deyimini tam olarak göstermektedir; yazılı metinlerden öğrenme söz konusu olduğu taktirde ise bilgi labirentinde kaybolmaktadırlar (Nielsen Hibbing \& Rankin-Erickson, 2003). Bu durum son derece ciddi bir problemdir. Bilginin anlaşılmasının bedeli, okuduğunu anlamamak olmamalıdır.

\section{SONUÇ}

Sinema filmlerinin çok etkin bir eğitim aracı olması sanat ve teknolojinin güçlerinden kaynaklanmaktadır. En derin kapsamlı, karmaşık ve yoğun bilgiler rahatlıkla çok geniş kitlelere ulaştırılabilmektedir. Karmaşık konseptlerin anlaşılmasının yanı sıra, bunlardan çok daha önemli olan tutum ve davranış bilgileri aktarılabilmekte ve kabul edilecek tarzlarda davranış modelleri yaratılabilmektedir. Sinema filmi aracı, herhangi bir eğitim modelinde belirlenmiş amaçlar doğrultusunda özel olarak yapılandırılarak rahatlıkla kullanılabilmektedir. $\mathrm{Bu}$ özellikler nedeniyle belirli amaçlar için hazırlanmış sinema filmleri giderek klasik ders kitaplarının yerini almaktadır. Ancak bu noktada okuduğunu anlamama şeklinde giderek artan çok ciddi bir problemi de beraberinde getirmektedir. Sinema filmlerinin toplumsallaştırmadaki rolü çok önemli ve vazgeçilmez olmakla birlikte, neden olduğu problemlere acil çözümler sağlanmalıdır.

\section{KAYNAKLAR}

Anonymous. (2007). Tools to Use. Italian America, 12(4), 21.

Appleford, S., \& Burton, V. (2008). Digital History: Using New Technologies to Enhance Teaching and Research. The Journal of American History, 94(4), 1329.

Bumpus, M. (2005). Using Motion Pictures To Teach Management: Refocusing The Camera Lens Through The Infusion Approach To Diversity. Journal of Management Education, 29(6), 792.

Frieden, J., \& Elliott, D. (2007). Teach with movies: using the storytelling power of movies to motivate students. Teacher Librarian, 34(3), 61. 
Griep, M. A., \& Mikasen, M. L. (2005). Based on a True Story: Using Movies as Source Material for General Chemistry Reports. Journal of Chemical Education, 82(10), 15011503.

Huczynski, A., \& Buchanan, D. (2004). Theory From Fiction: A Narrative Process Perspective On The Pedagogical Use Of Feature F1lm. Journal of Management Education, 28(6), 707.

Kramer, C. (2004). Accommodating Dialect Speakers in the Classroom: Sociolinguistic Aspects of Textbook Writing. Canadian Slavonic Papers, 46(1/2), 59.

Lewis, J. (2003). Public pedagogy. Afterimage, 30(3-4), 17.

Luch, J. (2007). Discovery Education Science Connection. Library Media Connection, 26(2), 61.

Luis Alvarez, J., Miller, P., Levy, J., \& Svejenova, S. (2004). Journeys To The Self: Usıng Movie Directors In The Classroom. Journal of Management Education, 28(3), 335.

Muller, V. (2006). Film as Film: Using Movies to Help Students Visualize Literary Theory. English Journal, 95(3), 32.

Nielsen Hibbing, A., \& Rankin-Erickson, J. (2003). A picture is worth a thousand words: using visual images to improve comprehension for middle school struggling readers. The Reading Teacher, 56(8), 758.

Norton-Meier, L. (2005). "Trust the fungus": Lessons in media literacy learned from the movies. Journal of Adolescent \& Adult Literacy, 48(7), 608.

Osborne, L. (2002). Clip art: Theorizing the Shakespeare film clip. Shakespeare Quarterly, 53(2), 227.

Pana Film. (2006). Ayrılık Dizisi. TV Filmi, . Erişildi Kasım 16, 2008, den http://www.ayrilik-dizisi.com/.

Paquette, M. (2003). Real life and reel life. Perspectives in Psychiatric Care, 39(2), 47-8. 
Sullivan Kerber, C., Clemens, D., \& Medina, W. (2004). Seeing is Believing: Learning about Mental Illness as Portrayed in Movie Clips. Journal of Nursing Education, 43(10), 479.

White, C., \& McCormack, S. The Message in the Music: Popular Culture and Teaching in Social Studies. The Social Studies, 97(3), 122.

Wilson, R. (2002). Be proud! Be brave! Be kind! Teacher Librarian, 30(2), 53.

Wilson, R. (2003). Making Social Issues Relevant with Documentaries. Teacher Librarian, 31(1), 51.

Xueshu Song. (2003). Anthropomorphic Multımedia Theater For Fundamental Engineerıng Problem Solving. International Journal of Instructional Media, 30(3), 295302. 